\title{
AVALIAÇÃO DAS CONDIÇÕES HIGIÊNICO-SANITÁRIAS EM PRAÇAS DE ALIMENTAÇÃO DE DOIS MERCADOS MUNICIPAIS DE CODÓ-MA
}

\section{EVALUATION OF HYGIENIC-SANITARY CONDITIONS IN FOOD STAMPS OF TWO MUNICIPAL MARKETS OF CODÓ-MA}

${ }^{1}$ Dalila da Silva Moraes Leite ${ }^{1}$; Maria José Magalhães da Silva ${ }^{2}$; Erica de Cassia Cantanhede ${ }^{3}$; Viviane Moraes Silva Coelho ${ }^{4}$; Cristiane Cardoso Barros ${ }^{5}$

DOI: https://doi.org/10.31692/978-65-991061-7-0.414-420

\section{INTRODUÇÃOO}

As feiras livres caracterizam não só como meio de comercialização de produtos alimentícios e abastecimento alimentar, mas como um espaço bastante representativo da tipicidade e das tradições multiculturais que retratam a composição dos povos que deram origem as nações ou comunidades, traduzidas entre outras características peculiares também pelos seus hábitos alimentares e cultura gastronômica (Dolzani e Jesus, 2004)

Feiras-livres são locais que possuem situações favoráveis para o crescimento e proliferação de microrganismos. Os problemas encontrados estão muitas vezes relacionados com as más condições higiênico-sanitárias das bancas, dos produtores, dos produtos comercializados de maneira incorreta e dos feirantes, que são considerados trabalhadores da economia informal (Matos et al., 2015).

O segmento de comida de rua em todo o mundo enfrenta contradições face aos seus aspectos positivos, como a geração de emprego e renda, bem como negativos decorrentes das condições higiênicas precárias e o risco de veiculação de doenças alimentares. A avaliação das características inerentes desse tipo de oferta de alimentos tem evidenciado a mobilização das gestões públicas no sentido de estabelecer sistemas de regulação para o setor (RANE, 2011).

Este tipo de alimentação é fomentado pelo crescente hábito das pessoas de fazerem refeições rápidas fora da residência, o que torna esse costume um grave problema de saúde pública, devido às falhas no processo de produção destes alimentos e as possíveis doenças por eles transmitidas (OLIVEIRA et al., 2003).

Dentre os principais fatores que podem ocasionar alterações na qualidade dos alimentos destacam-se: a falta de infraestrutura e espaço adequado nos quiosques, a ausência de equipamentos de conservação bem como a falta de água encanada, conservação e higienização inadequadas dos alimentos, dos utensílios e dos manipuladores e a presença de vetores e pragas (LUCCA; TORRES, 2002; NASCIMENTO; BARBOSA; CHIRADIA, 2007; 
SOUSA et al., 2007).

Os alimentos podem ser frequentemente associados a surtos de doenças transmitidas por alimentos (DTAs), sendo necessário um controle higiênico-sanitário adequado de acordo com as Boas Práticas de Fabricação (BPF). Entretanto, a real avaliação desse problema no Brasil é comprometida, haja vista que a notificação da ocorrência desse tipo de doenças não é compulsória (MALLON; BARTOZOLO, 2004; LUCCA; TORRES, 2002).

A manipulação inadequada de alimentos é uma das principais causas de surtos de doenças de origem alimentar, relacionando-se diretamente com a contaminação dos alimentos. Portanto, a higiene dos manipuladores de alimentos é um fator que deve ser gerenciado e controlado para não comprometer a segurança dos alimentos e evitar contaminações e toxinfecções (Nolla, 2005).

A aplicação das Boas Práticas (BP) é de grande importância visto que é uma ferramenta que objetiva determinar diretrizes que normalizem e definam procedimentos que direcionem a fabricação de um produto ou a execução de um serviço (Gomes \& Rodrigues, 2006).

O presente estudo visou avaliar as condições higiênico-sanitária dos estabelecimentos que oferecem serviços de alimentação por meio da aplicação de check-list em duas feiras livres do município de Codó Maranhão, quanto a Resolução SS-196 (CVS, 1998), as quais contemplam aspectos envolvendo a instalação do local, utensílios e manipuladores.

\section{METODOLOGIA}

Foram avaliadas condições higiênico-sanitárias das praças de alimentação das feiraslivres do município de Codó Maranhão, durante o mês de Maio de 2018. A pesquisa constituiu da aplicação de um checklist que contou com 59 itens de verificação das Boas Práticas, agrupados por assunto, em cinco blocos. Os preenchimentos foram feitos por meio de observações no próprio local. As opções de respostas foram: "sim” (S), quando o estabelecimento atendeu ao item observado; "não" (N), quando o mesmo não atendeu e, "não se aplica" (NA), quando o item não foi pertinente à avaliação do estabelecimento checado.

Para a coleta de dados, utilizou-se uma lista de verificação a Ficha de Inspeção, Adaptada do modelo da Vigilância Sanitária - Ficha de Inspeção de Estabelecimentos na área de alimentos, Resolução SS-196 (CVS, 1998). A lista contemplava os seguintes requisitos: Situação e condições da identificação (24 itens); Equipamentos e Utensílios (10 itens); Pessoal na área de produção/manipulação/venda (6 itens); Procedência controlada (4 itens); Fluxo de produção/manipulação venda e controle de qualidade (14 itens), sendo os requisitos 
avaliados como adequado, inadequado ou não se aplica. Após, calculou-se o percentual de adequação geral e por requisitos, sendo os estabelecimentos classificados em DEFICIENTE quando apresentarem até $60 \%$ de atendimento dos itens; REGULAR com 61 a $80 \%$ de atendimento dos itens; BOM de 81 a $90 \%$ de atendimento dos itens; MUITO BOM de 91 a 99\%; e EXCELENTE $100 \%$.

Os resultados foram analisados por meio de estatística descritiva simples (média e porcentagem), com a apresentação em tabelas de frequência.

\section{RESULTADOS E DISCUSSÃO}

Os resultados obtidos a partir da aplicação do checklist nas duas praças de alimentação podem ser observados na tabela 1 . As praças de alimentação foram consideradas deficientes de acordo com a classificação apresentando resultado de 25,95 no estabelecimento A e no estabelecimento B com 26,55.

Tabela 1 - Resultados dos blocos obtidos a partir da aplicação do checklist em duas praças de alimentação do município de Codó - Ma.

\begin{tabular}{c|c|c}
\multirow{2}{*}{ ITENS AVALIADOS } & \multicolumn{2}{|c}{ PRAÇA DE ALIMENTAÇÃO } \\
\cline { 2 - 3 } & A & B \\
\hline $\begin{array}{c}\text { Situação e condições da } \\
\text { identificação (\%) }\end{array}$ & 2,8 & 3,4 \\
\hline $\begin{array}{c}\text { Equipamentos e utensílios } \\
(\%)\end{array}$ & 0 & 0 \\
\hline $\begin{array}{c}\text { Pessoal na área de } \\
\text { produção/manipulação/venda } \\
(\%)\end{array}$ & 0,25 & 0,25 \\
\hline $\begin{array}{c}\text { Produto pronto/embalagem } \\
(\%)\end{array}$ & 10 & 10 \\
\hline $\begin{array}{c}\text { Fluxo de produção / } \\
\text { manipulação/ venda e controle } \\
\text { de qualidade (\%) } \\
\text { TOTAL }\end{array}$ & 12,9 & 12,9 \\
\hline
\end{tabular}

No item Situação e condições da identificação (Tabela 1), apresentaram média de $2,8 \%$ o estabelecimento A e 3,4\% o B de adequação. A localização dos dois estabelecimentos não é adequada, observou-se a saída do lixo pelo mesmo local onde entram as matériasprimas, proporcionando uma possível contaminação cruzada. Na área externa da vizinhança foi possível observar focos de insalubridade, esgoto exposto, lixo, objetos em desuso. O acesso é adequado, direto e independente, o que facilita o acesso de fornecedores, embora seja observado que o layout é impróprio, devido à possibilidade de contaminação cruzada entre 
alimentos crus e cozidos. A edificação e as instalações devem ser projetadas de forma a possibilitar um fluxo ordenado e sem cruzamentos em todas as etapas da preparação de alimentos e a facilitar as operações (BRASIL, 2004).

Em relação à edificação na praça de alimentação $\mathrm{B}$ o piso apresentava-se em bom estado de conservação estando livre de defeitos, rachaduras, trincas e buracos, e paredes com acabamento liso, impermeável, lavável, e em bom estado de conservação, ao contrário da praça de alimentação A. A praça de alimentação A e B tinham falta de proteção nas aberturas inferiores para proteção contra insetos; luminárias sem proteção contra quebra e contaminação, e não possuem o teto em acabamento liso, impermeável, lavável, e em bom estado de conservação, e não são provida de telas milimetradas. As aberturas externas das áreas de armazenamento e preparação de alimentos devem ser providas de telas milimetradas para impedir o acesso de vetores e pragas urbanas, sendo as mesmas removíveis de modo a facilitar na limpeza periódica (BRASIL, 2004). Nos dois estabelecimentos não possui lavatórios exclusivos para higienização das mãos na área de manipulação, sendo feita a higienização das mãos e da matéria prima e utensílios no mesmo local. De acordo com a Portaria SVS/MS nº. 326, 30 de julho de 1997, toda Unidade de Alimentação e Nutrição deve ter instalações adequadas e convenientes para a lavagem exclusiva das mãos na área de produção, de forma a minimizar a contaminação, uma vez que esta poderá ocorrer através das próprias mãos dos manipuladores (BRASIL, 1997). Foi observado às instalações sanitárias somente no estabelecimento B foram observadas em péssimo de estado de conservação, não sendo separados por sexo e localizados em comunicação direta com a área de preparação, sendo que em nenhuma continham vestiários. Nos dois estabelecimentos foi observado agua potável, sendo que somente o estabelecimento B foi observado caixa d'agua.

No item Equipamentos e utensílios (Tabela 1), não apresentou nenhuma adequação com $0 \%$ de conformidade o que é considerado um ponto alarmante, resultados semelhantes do estudo realizado por Figueiredo et al. (2007), no qual se constatou que os equipamentos e utensílios mesmo sendo de fácil limpeza e desinfecção, não apresentavam bom estado de conservação e higiene. A higienização de equipamentos e utensílios foi considerada inadequada nos dois locais, como também os utensílios armazenados de forma desordenada e desprotegidos contra sujidades, insetos e roedores. Os equipamentos e utensílios oferecem risco de contaminação dos alimentos. Portanto, há uma necessidade de adequação do processo de higienização através da conscientização dos manipuladores de alimentos, a fim de garantir a qualidade das refeições coletivas. (Alves e Ueno, 2010). Os principais aspectos negativos dos setores de produção de alimentos estão relacionados à higiene do manipulador de 
alimentos e à má higienização de equipamentos e utensílios. Ressalta-se a importância de se possuir móveis e utensílios lisos, impermeáveis e laváveis, de material adequado e em bom estado de conservação para se garantir a segurança microbiológica dos alimentos oferecidos (SÃO PAULO, 2011; TONDO; BARTZ, 2011).

Em relação ao item Pessoal na área de produção/manipulação/venda (Tabela 1), os dois estabelecimentos obtiveram a mesma porcentagem de adequação $0,25 \%$, as roupas não estavam adequadas, sem o uso dos EPI's necessários. Foi observado que no estabelecimento B havia ausência parcial de tocas e total no A. Não havia nenhum registro de treinamento de manipuladores de alimentos. Segundo a RDC no 216/2004, os manipuladores necessitam ter asseio pessoal, com uniformes compatíveis com a atividade, conservados e limpos. Além disso, os manipuladores de alimentos devem ser vistoriados e capacitados periodicamente em higiene pessoal, em manipulação higiênica dos alimentos e em doenças transmitidas por alimentos.

O item Produto pronto/embalagem (Tabela 1), apresentou 10\% de adequação para os dois estabelecimentos, sendo os alimentos expostos com características organolépticas normais (cor, sabor, odor, consistência e aspectos), sem alteração. Porém as condições de tempo e temperatura de conservação dos produtos expostos à venda não eram adequadas, já que os alimentos prontos não eram mantidos nas temperaturas adequadas. Tempo longo de permanência das preparações quentes em temperaturas inadequadas aumenta a possibilidade de consumo de alimentos em condições higiênicas insatisfatórias. Desta forma, há risco para a saúde dos clientes. A legislação estabelece que após serem submetidos à cocção, os alimentos preparados devem ser mantidos em condições de tempo e de temperatura que não favoreçam a multiplicação microbiana. Para conservação a quente, os alimentos devem ser submetidos à temperatura superior a $60^{\circ} \mathrm{C}$ por, no máximo, 6 (seis) horas. O binômio tempo/ temperatura a que as preparações são expostas durante a etapa de distribuição das refeições tem grande importância para a segurança dos alimentos. Deve ser estabelecido na unidade controle rigoroso de forma a impedir a multiplicação bacteriana, pois a manutenção do alimento em temperaturas não adequadas e o tempo de espera longo tem consequências diretas na qualidade final do produto (SOARES et al, 2009).

No item Fluxo de produção/manipulação venda e controle de qualidade (Tabela 1), a porcentagem de adequação dos dois estabelecimentos foi a mesma de 12,9\%, o item que apresentou maior adequação. O fluxo de produção é um item particularmente importante para todas as unidades produtoras/manipuladoras de alimentos, principalmente nos locais onde há volume de produção. O fluxo deve ser linear de um só sentido, evitando a contaminação 
cruzada: locais para pré-preparo "área suja” e preparo "área limpa” isolados, pois a separação física é necessária em estabelecimentos com grande produção. Nos estabelecimentos analisados o fluxo de produção foi considerado inadequado, pois todos os processos eram feitos no mesmo local favorecendo a contaminação cruzada comprometendo a qualidade final do produto.

\section{CONSIDERAÇÕES FINAIS}

Diante do trabalho realizado constatou-se que as praças de alimentação estudadas, não possuem as mínimas condições básicas para o correto controle higiênico-sanitário, e que as boas práticas nos estabelecimentos que compõem as praças necessitam ser aplicadas em todas as etapas que envolvem a manipulação de alimentos.

Sugere-se que as autoridades sanitárias do município possam editar normas que regulamentem as medidas de segurança higiênico sanitárias para os estabelecimentos que comercializam comidas nas praças de alimentação, constituindo assim uma fiscalização habitual e de forma cabível. Além disso, devem-se promover programas de capacitação e adoção de programas para os manipuladores de alimentos da cidade de Codó-MA proporcionando assim uma segurança alimentar aos consumidores.

\section{REFERÊNCIAS}

ALVES, M.G.; UENO, M. Restaurantes self service: segurança e qualidade sanitária dos alimentos servidos. Revista de Nutrição, v.23, n.4, p.573-580, 2010.

DOLZANI, M.; JESUS, G.M. (2004). O direito à cidade: cem anos de feira livre na cidade do Rio de Janeiro. Disponível em: http://www.uerj.br

MATOS, J.C; BENVINDO, L.R.S.; SILVA, T.O.; CARVALHO, L.M.F. (2015). Condições higiênico-sanitárias de feiras livres: uma revisão integrativa. Gestão e Saúde, 6(3),2884-93.

OLIVEIRA, A. M.; GONÇALVES, M. O.; SHINOHARA, N. K. S.; STAMFORD, T. L. M. Manipuladores de alimentos: um fator de risco. Higiene Alimentar, São Paulo, v.17, n.114/115, p.12-19, 2003.

Rane, S. (2011). Street Vended Food in Developing World: Hazard Analyses. Indian Journal of Microbiology, 51, 100-106.

LUCCA, A.; TORRES, E. A. Condições de higiene de "cachorro-quente" comercializado em vias públicas. Revista de Saúde Pública, São Paulo, v. 36, n. 3, p. 350-352, jun. 2002.

NASCIMENTO, G. A.; BARBOSA, J. S.; CHIRADIA, A. C. N. Levantamento das condições sanitárias dos quiosques das praias de Camburi e Curva da Jurema, da cidade de Vitória, Espírito Santo. Revista Higiene Alimentar, São Paulo, v. 21, n. 152, p. 18-24, jun. 2007. 
SOUSA, J. M. B. et al. Avaliação do perfil higiênico - sanitário dos estabelecimentos comerciais e manipuladores de carne bovina na feira livre de bananeiras - PB.

MALLON, C.; BORTOZOLO E. A. F. Q. Alimentos comercializados por ambulantes: uma questão de segurança alimentar. Publicatio UEPG: Ciências Biológicas e da Saúde, Ponta Grossa, v. 10 n. 3/4, p. 65-76, set./dez. 2004.

NOLLA, A. C.; CANTOS, G. A. (2005). Relação entre a ocorrência de enteroparasitoses em manipuladores de alimentos e aspectos epidemiológicos em Florianópolis, Santa Catarina, Brasil. Caderno de Saúde Pública, 21(2), 641-645.

GOMES, H. V.; RODRIGUES, R. K. (2006). Boas práticas de fabricação na indústria de panificação. In: Anais do XXIV Encontro Nacional de Engenharia de Produção, Fortaleza, Brasil.

BRASIL. Ministério da Saúde. ANVISA - Agência Nacional de Vigilância Sanitária. RESOLUÇÃO-RDC Nº 216, DE 15 DE SETEMBRO DE 2004, Dispõe sobre Regulamento Técnico de Boas Práticas para Serviços de Alimentação. BRASIL, 2004.

BRASIL. Ministerio da Saude. Secretaria de Vigilancia Sanitaria. Portaria $n^{\circ} 326$, de 30 de julho de 1997. Regulamento técnico sobre as condições higiênico-sanitarias e de boas práticas de fabricação. Diário Oficial da União, de 01/08/97.

FIGUEIREDO, E. S. E.; IMBELLONI, M. F.; ELESBÃO, H. S.; SANTOS, A. F. Avaliação das condições Higiênico-sanitárias de manipulação de comercialização de produtos de origem animal nas feiras livres do município de Cuiabá - MT. Revista Higiene Alimentar, São Paulo, v. 21, n. 148 , p. 38-42, 2007.

SOARES, A. D. N.; MONTEIRO, M. A. M.; SCHAEFER, M. A. Avaliação de binômio tempo e temperatura em preparações quentes de restaurante universitário. Hig. Aliment., v. 23, n. 174/175, p. 36-41, 2009.

CVS - Centro de Vigilância Sanitária. Resolução SS-196. Roteiros e guias de inspeção em Vigilância Sanitária. 29/12/1998. Disponível em: .

QUINTILIANO, C. R. et al. Avaliação das condições higiênico-sanitárias em restaurantes, com aplicação de ficha de inspeção baseada na legislação federal, RDC 216/2004. Hig. Aliment., v. 22, n. 160, p. 25-30, 2008.

SOARES, A. D. N.; MONTEIRO, M. A. M.; SCHAEFER, M. A. Avaliação de binômio tempo e temperatura em preparações quentes de restaurante universitário. Hig. Aliment., v. 23, n. 174/175, p. 36-41, 2009. 